W Child - "Memory, Expression, and Past-Tense Self-Knowledge” - Philosophy and Phenomenological Research, 73, 2006, 54-76

\title{
Memory, Expression, and Past-Tense Self-Knowledge
}

\author{
William Child
}

How should we understand our capacity to remember our past intentions, wishes, beliefs, and so forth? And what, if anything, can we learn from Wittgenstein's treatment of the topic?

A central theme in Wittgenstein's later philosophy is that thought and language are based in natural, pre-linguistic reactions. ${ }^{1}$ To give two examples: there is the suggestion that the first-person use of the word "pain" is acquired as a learned addition to pre-linguistic expressions of pain; and there is the idea that our ascription of sensations to others is a development from our natural, pre-linguistic tendency to respond with sympathy to their behavioural expressions of pain. ${ }^{2}$ Wittgenstein applies elements of the same general approach to the self-ascription of propositional attitudes. Thus, he suggests that we acquire the concept of belief, for example, not via introspective acquaintance with internal states of belief but, in part, by learning to judge "I believe that p" in circumstances where we already make the simple judgement "p". 3 And he holds that, in an important class of cases, self-ascriptions like "I believe it's raining", "I hope he'll come”, or "I intend to leave”, are immediate expressions of the subject's attitudes; they are not reports made on the basis of self-observation. There are certainly elements in Wittgenstein's treatment that are unappealing: for example, his apparent assumption that when a self-ascriptive judgement expresses an attitude, it cannot simultaneously describe the subject as having that attitude. But there is a growing sense that Wittgenstein's work, shorn of some unattractive and inessential features, contains the basis for a way of understanding self-knowledge that does better than the various alternatives. ${ }^{4}$

Most Wittgenstein-inspired discussions of self-knowledge and self-ascription have concentrated exclusively on the case of self-ascribing one's current attitudes. ${ }^{5}$ But Wittgenstein himself applies the same ideas to the self-ascription of past attitudes. He says, for example, that a report of one's past intention is standardly a response and is not made "on grounds of self-observation” (PI §659). He urges us to "look on the language-game [of telling someone that a time ago I had such-and-such a wish] as the primary thing” (PI §656). And he suggests that the way we acquire the concept of our past intentions is by learning to produce retrospective expressions of those intentions (RPP i 163). But Wittgenstein's treatment of the past-tense case - as well as the topic of past-tense self-knowledge in general - has been relatively neglected in the literature. This paper aims to correct that neglect.

I pursue three main questions. First, what is Wittgenstein's point in taking the 
"language-game" of reporting past attitudes as "the primary thing": does it yield a successful treatment of the epistemology and metaphysics of past-tense self-ascription; and does it give a plausible account of our acquisition of the concept of our own past attitudes? Second, does Wittgenstein's discussion suggest, as some have thought, that there are cases in which the identity of someone's attitude at a particular time is determined, not by anything that was true of her at the time, but rather by her retrospective self-ascription of that attitude? Third, and running through the whole discussion, what in general is the relation between our past attitudes, on the one hand, and our present beliefs about them, on the other? I start with this last question.

\section{Realism and anti-realism about past attitudes}

There are, broadly speaking, two models of the relation between our past intentional states and our present beliefs about them. We ordinarily take a fundamentally realist view. When I remember what I believed or intended at some previous time, there is (we think) a fact of the matter about what I did believe or intend, independent of my subsequent judgement or report about it. ${ }^{6}$ My judgement is true (if it is) because the attitude it ascribes me is an attitude I had at the time, in advance of any subsequent recollection. On this view, understanding the reliability of our memory of our attitudes is a matter of understanding how our past-tense selfascriptions succeed in tracking the facts about the past attitudes themselves.

The alternative, anti-realist, approach reverses that picture: the present beliefs or reports come first; the past attitudes are a projection into the past of those beliefs or reports. On such a view, to put it crudely, it is a subject's present disposition to judge that she believed that $\mathrm{p}$ or intended to $\Phi$ that makes it true that she did. So the reason our judgements about our past intentional states are generally right is that they are actually constitutive of the truths they seem to report. ${ }^{7}$

Anti-realism of this sort faces obvious objections. In many cases, as well as the later self-ascription of intention, there will also have been self-ascriptions, or other manifestations of intention, at the earlier time. And those earlier manifestations testify to the presence of something about the subject at the time in virtue of which it was already true that she intended to $\Phi$, in advance of the later self-ascription. But the anti-realist view is less obviously implausible for properties and attitudes that the subject did not self-ascribe or manifest in other ways at the time. And cases of this sort figure prominently in Wittgenstein's discussions. For example:

Interrupt a man in quite unpremeditated and fluent talk. Then ask him what he was going to say; and in many cases he will be able to continue the sentence he had begun (Z 38).

In such cases, there is no contemporary manifestation with which the subsequent report could agree (or conflict). So it is not obviously hopeless to say that, if the man declares, "I was going to say that the reforms are misguided", what makes it true that that is what he was going to say is just his subsequent declaration. However, even in these cases, we find it hard to 
accept the anti-realist view. Something said now may be the best way of telling that some earlier state of affairs obtained. But, we are strongly inclined to insist, if it is true that someone was about to say that the reforms were misguided, there must have been something about him at the time in virtue of which it is true; it cannot be made true retrospectively by something he later did or said.

However, the fact that we are strongly inclined to insist on something does not show that it is true. Maybe our intuitive realism about past intentional states is a mistake. Or maybe it is an empty battle cry - a slogan that we find ourselves inclined to insist on when we reflect on our ordinary ways of thinking, but which turns out to have no genuine content. ${ }^{8}$ So we cannot dismiss questions about the realist model out of hand.

\section{The immediacy of past-tense self-ascriptions}

What does Wittgenstein think about past-tense self-ascriptions? He is clear about what it would be wrong to say about their phenomenology and epistemology. ${ }^{9}$ We can summarize his negative views as follows. When I think about my past intentions, my memory may summon up experiences, thoughts, words and actions that I enjoyed, entertained, uttered or performed at the time. But remembering an intention is not a matter of remembering any of these things; for none of them is, or suffices for, the intention. Nor is it a matter of interpreting such data, or inferring or reading off the intention from the data. For one thing, I generally judge what I intended immediately, without considering remembered experiences, or thoughts, or utterances at all. ${ }^{10}$ For another thing, the totality of such data would in any case often give only very weak grounds for such an inference, even if supplemented by information about the antecedents and surroundings. ${ }^{11}$ In Wittgenstein's view, when I judge what I intended to do or say, my judgement is typically not based on anything at all; I simply remember that I was going to do this or say that. ${ }^{12}$

These negative claims are persuasive. But they are neutral between the realist and anti-realist models. Wittgenstein's basic point is that past-tense self-ascriptions are immediate and groundless; they are not based on introspected phenomenology or on inference from one's behaviour. And that point can be accommodated by both realist and anti-realist.

The realist will point out that the epistemic immediacy of our past-tense selfascriptions is clearly compatible with realism about what makes them true. I can say what my name is, or report the position of my arm, immediately and without inference. But that does not show that my sincerely and attentively judging that my name is NN makes it the case that it is, or that my judgement about the position of my arm constitutes its position as being what it is. ${ }^{13}$ The same is true, says the realist, for my reports of my past attitudes.

The anti-realist, for his part, will say that it is no surprise that our reports of our past attitudes are groundless; for when we make such reports, he thinks, there is nothing that we are detecting and, therefore, nothing for our reports to be grounded in. Of course, the antirealist acknowledges, we call the capacity to make ungrounded reports of our past attitudes a form of memory. After all, like other memory-reports, these reports are about the past, and 
they are standardly accepted as true. But we must not assume that every case in which we talk about memory should be construed in realist terms. Wittgenstein cautions against assuming that every use of the past-tense is the same ${ }^{14}$. And in "getting a bird's-eye view of the use of the word 'remember", 15 perhaps we will have to acknowledge that, though many cases of remembering should be conceived along realist lines, others should not.

Some readers of Wittgenstein will protest that my question, "Should we take a realist or an anti-realist view of self-ascriptions of past attitudes?”, is fundamentally nonWittgensteinian. The right attitude, they will say, is something like this: We have a practice of reporting our past attitudes. In appropriate cases, we call such reports "memories” and say that they express knowledge of the subject's past attitudes. But we can go no further than describing these facts about our practice. To press the question, "Realism or anti-realism about memory of intentional states?”, is in effect to ask whether the phenomenon we call "remembering an intention" is really a form of memory, whether we are right to call it remembering. And such attempts to justify, criticize, or explain our practices are always a mistake. If it is correct, by the rules for the use of our concepts "memory" and "intention", to call something a memory of an intention, then it is a memory of an intention; there is, and can be, no more to say than that.

There are large issues here, which I cannot now discuss in detail. I will simply indicate, briefly and dogmatically, why I do not think that the questions I am pressing must be unWittgensteinian. Wittgenstein's own work gives us the basis for two important ideas: the idea that a concept has a point as well as a set of rules, that the point is not exhaustively defined by the rules, and that grasp of the point may be used to gain some reflective perspective on the rules ${ }^{16}$; and the idea that we can reflect on the sort of use a concept has, and that such reflection may show that concepts that look similar in some ways are very different in others. ${ }^{17}$ Asking whether we should understand past-tense self-ascriptions on the realist or the anti-realist model need not require resources beyond these.

\section{Disposition-based realism}

Suppose someone says, "Napoleon was crowned in 1804". The question arises, did he mean the man who won the Battle of Austerlitz? The discussion proceeds:

"But after all if someone asks you 'did you mean the very man who won the battle of Austerlitz' you will say 'yes'. So you meant that man when you uttered the sentence.” - Yes, but only in the kind of way that I then knew also that 6 × $6=36$.

The answer "I meant the victor of Austerlitz" is a new step in our calculus. The past tense is deceptive, because it looks as if it was giving a description of what went on "inside me" while I was uttering the sentence. (PG 103)

On the natural way of reading such passages, Wittgenstein's target is not realism about past intentional properties itself, but only a particular philosophical view of what that realism involves. He does not challenge the thought that, if it is true that, when I uttered the sentence, 
I meant the man who won the battle of Austerlitz, then it is true in virtue of something about me at the time. What he objects to is the philosophical view that what makes it true must be something that "went on "inside me"” at the time - whether it be a thought running through my mind, a mental image, an "act of meaning", or anything else. In place of that view, Wittgenstein thinks that the fact that I meant the man who won the battle of Austerlitz is linked to facts about the dispositions and abilities I had at the time - e.g., the fact that, other things being equal, had I been asked whether the man I meant was the one who won the battle of Austerlitz, I would have said 'yes'. We could call this view disposition-based realism about past intentional phenomena.

A view of just this kind can be found in many passages in Wittgenstein. For example: Is it correct for someone to say: "When I gave you this rule, I meant you to . . . . in this case”? Even if he did not think of this case at all as he gave the rule? Of course it is correct. For "to mean it" did not mean: to think of it. But now the problem is: how are we to judge whether someone meant such-and-such? - The fact that he has, for example, mastered a particular technique in arithmetic and algebra, and that he taught someone else the expansion of a series in the usual way, is such a criterion (PI §692).

That puts the point in epistemological terms: we judge whether someone meant such-and-such by reference to his mastery of a technique (and, we could add, we judge whether someone has mastered a technique in part by seeing whether he does in fact get correct results in some sufficiently large range of cases). ${ }^{18}$ But it is plausible to think that Wittgenstein would endorse the metaphysical counterpart of this claim; it is not just that we tell what someone meant by reference to their abilities and dispositions; it is the fact that someone had such abilities and dispositions that makes it true to say that they meant so-and-so.

Now there are well known problems for any attempt to identify intentional states with linguistic or behavioural dispositions, or to reduce them to such dispositions. For one thing, behaviour results only from combinations of attitudes; so there can be no one-to-one correlation. For another thing, our actual dispositions are vulnerable to mistake and malfunction. ${ }^{19}$ So we must allow that it might be true that you know that $6 \times 6=36$, say, and that you meant someone to give the answer " 36 " when they calculated $6 \times 6$, even though, had you been asked at the time what answer she should give, you would in fact have said " 38 ". On the other hand, we would not allow that someone could know that 6 x $6=36$ even if they never got the correct answer to a multiplication problem. Evidently, more needs to be said about the way in which a subject's attitudes are answerable to her abilities and dispositions. But however exactly this relation is to be explained and understood, the crucial thing for present purposes is this. The basic realist intuition is that what mental properties a subject has at a time is a matter of the abilities and dispositions she has at that time, not a matter of her later dispositions; in particular, it is not a matter of her later disposition to self-ascribe earlier intentions, meanings, wishes and so on.

I suggest that Wittgenstein's view of past attitudes is a disposition-based realism of this kind. But there are lines of thought in Wittgenstein that might suggest a less realist view. 
W Child - "Memory, Expression, and Past-Tense Self-Knowledge" - Philosophy and Phenomenological Research, 73, 2006, 54-76

In what follows, I shall examine two such strands. I shall argue that, though each has much to tell us about Wittgenstein's views, and about memory of intentional properties itself, neither of them supports any kind of anti-realism about past intentional properties. ${ }^{20}$

\section{The primariness and primitiveness of reports of past intentions}

One strand in Wittgenstein that may suggest a kind of anti-realism about past intentional states comes out in his remarks, which I noted at the outset, about the primitiveness of our verbal reports of those states. Thus, for example, in considering the practice of reporting past wishes or intentions, he advises:

Look on the language-game [of telling someone that a time ago I had such-and-such a wish] as the primary thing. And look on the feelings, etc., as you look on a way of regarding the language-game, as interpretation (PI §656).

One way of putting our ordinary, realist view would be to say that the past wish or intention is the primary thing: the subsequent verbal report is secondary; it is made true (or false) by the past existence (or not) of the relevant wish or intention. It is easy to read Wittgenstein's idea as a reversal of that view: the verbal report is the primary thing; so the past wish or intention has no existence independent of the report one subsequently makes (or is disposed to make); it is simply a projection of the present report back into the past. ${ }^{21}$

But does Wittgenstein's stress on the primariness of the language-game of reporting past attitudes, and on the primitiveness of such reports themselves, really indicate a non-realist view of the past attitudes? Everything depends on the sort of priority he has in mind. If he is claiming a metaphysical priority for a person's present reports of her past attitudes, his position will indeed imply some kind of anti-realism. But suppose his thought is only that the verbal reports are epistemically primitive, and that they are primary in terms of conceptacquisition. In that case, there need be no tension with our ordinary, realist view. How, then, should Wittgenstein's remarks be taken?

As I said at the outset, the idea that thought and language are based on natural, prelinguistic reactions is a central theme in Wittgenstein's later philosophy. But the application of that idea may work differently in different cases. We can work up to the case of past-tense self-ascription by looking first at two other cases: the case of sensations and the case of other minds.

\section{4.i Sensations}

In some cases, Wittgenstein's appeal to the natural, pre-linguistic basis of a "language-game" has clear metaphysical implications. That seems true of his suggestion that "words for sensations [are] tied up with . . natural expressions of sensation” (PI §256). Wittgenstein introduces this suggestion in connection with a question about concept-acquisition: "how does a human being learn the meaning of the names of sensations?” (PI §244). And the immediate point of the suggestion is to show how we might acquire the concept of pain, given that it 
cannot be acquired by inward ostensive definition. But Wittgenstein's comments about natural expressions are clearly also connected with the idea that sensations are not "private objects", items with identity conditions that are wholly independent of any links with the subject's behaviour or external circumstances. And that is a metaphysical idea; a creature's exhibiting certain sorts of natural, expressive behaviour is a condition for its having sensations, not just a condition for its being able to learn the meanings of sensation words.

\section{4.ii Other minds}

In other cases, the appeal to primitive, pre-linguistic reactions does not imply that the reactions have any constitutive role. Consider, for example, Wittgenstein's comments about our relation to others' pains:

it is a primitive reaction to tend, to treat, the part that hurts when someone else is in pain; and not merely when oneself is - and so to pay attention to other people's painbehaviour, as one does not pay attention to one's own pain behaviour.

But what is the word "primitive" meant to say here? Presumably that this sort of behaviour is pre-linguistic: that a language-game is based on it, that it is the prototype of a way of thinking and not the result of thought.

\section{(Z $\S \S 540-1)$}

Here, the idea that our reactions to others' pains are primitive is used to make two points.

The first point is epistemic. An instinctive reaction by one pre-conceptual creature to another's pain involves no inference or reasoning. As the creature develops conceptual capacities, its reactions develop; they come to include a tendency to apply the concept pain and to form the belief that the other creature is in pain. But though the nature of the reactions changes, their epistemological immediacy does not. When I believe that someone is in pain, I do not standardly reach that belief by observing his behaviour and inferring that he is in pain: I form the belief immediately, without inference. ${ }^{22}$

Wittgenstein's second point is about concept-acquisition: grasp of the concept of others' pain is a development or extension of a pre-linguistic reaction towards others' pain. When I acquire the concept pain, as applied to others, my task is made relatively easy by the fact that, through my pre-linguistic reactions, I already distinguish cases where others are manifestly in pain from cases where they are not. Our behavioural reactions to others' pains are primary because they pre-date, and are the basis for, articulate thought about those pains.

This is, in the first instance, a claim about how we do in fact come to acquire the concept of others' pains. As such it seems entirely plausible: children do exhibit ways of behaving appropriately towards others' pains before they could be said to grasp the concept of pain; and it is plausible that part of the process of coming to grasp that concept is learning to say "Her toe hurts" or "He's got a stomach ache" in circumstances that the child already distinguishes in her sympathetic behaviour. Wittgenstein does not make the stronger claim that we couldn't grasp the concept of others' pain if we did not have this kind of natural reaction to others. But does anything he says suggest this stronger view? 
Wittgenstein does argue that I could not acquire the concept of others' pain by starting from a purely introspective conception of my own pain and working outwards from there to construct a concept of pains that are not my pains. ${ }^{23}$ But that does not establish that one can acquire the concept only by building on a primitive, pre-conceptual tendency to react sympathetically towards others' pains. For all that has been said so far, one could acquire the idea that others can be ascribed pain on the basis of their behaviour, and the capacity to make such ascriptions, without any prior tendency to behave towards others with sympathy or concern. One could then go on to learn to behave with concern towards someone who is in pain. So one's sympathetic behaviour would be "the result of thought" rather than "the prototype of thought". That is not how it is with us. But it is hard to see why there couldn't be cases in which the standard order of acquisition was reversed. Indeed, that may well be how things work for some people with autism. Even if an autistic child has little or no natural tendency to treat other people as sentient beings with intentional states, or to think of them as such, she can acquire the concepts of sensory and intentional states and learn how to apply them to others on the basis of their situation and behaviour. ${ }^{24}$ And she can go on from there to learn how to interact successfully with others - including learning how to respond appropriately to others' pain.

So, in stressing the primitiveness of our reactions to others' pain, Wittgenstein makes two points: one about epistemology, the other about concept-acquisition. But he does not suggest that our reactions to others' pains are part of the metaphysics of the states they are reactions to. Our reactions do not play a constitutive role: either in the weaker sense, in which one person's pains would only count as pains if others had some tendency to treat them sympathetically; or in the stronger sense, in which (absurdly) the existence of one person's pains would actually be constituted by other people's reactions to them. ${ }^{25}$

\section{4.iii Past-tense self-ascriptions of intentional states}

In some cases, then, Wittgenstein's talk of primitive expressions or reactions carries a metaphysical message. In others, it does not. What points is he making when he calls a report of one's past intention a response (PI §659), and says that the language-game of telling someone about a past wish or intention should be regarded as the primary thing? I will consider that question in three stages: epistemology, metaphysics, and concept-acquisition.

\section{4.iii.a The past-tense case: epistemology}

The epistemic point of calling a report of one's past intention a response is the one we have already seen: in ordinary cases, my knowledge of my past intentions is immediate and ungrounded; it is not a report of data provided by introspection or observation; nor is it an inference from, or interpretation of, such data. As I have said, this seems to me to be correct.

\section{4.iii.b The past-tense case: metaphysics}

Does the fact that we can make immediate, groundless reports of our past intentions and 
wishes have any metaphysical import? I said that, for the case of pain, Wittgenstein's stress on the idea of primitive, pre-linguistic expressions of pain is part of a view about the metaphysics of experience. He seems to suggest something similar for natural, pre-linguistic expressions of a creature's current intentions:

What is the natural expression of an intention? - Look at a cat when it stalks a bird; or a beast when it wants to escape (PI §647). ${ }^{26}$

Exhibiting natural expressions of intention of this sort seems a precondition for a creature to have intentions (or proto-intentions) at all. And when we turn from the pre-linguistic to the linguistic case, it is very plausible that the ability to give linguistic expression to one's current intentions - to state one's intentions without self-observation or self-interpretation - is essential to the possession of full-blown intentions by a conscious, language-using subject. Suppose one had no such immediate access to one's own current intentions. So one could tell what one intended only by observing one's situation and behaviour and ascribing intentions to onself in the same kind of way that one ascribes them to others. If that were really one's only way of knowing one's current intentions, it could not be the case that one's intentions were formed by one's decisions about what to do, in the light of one's reasoning about the options. But intention just is a state that is formed and controlled in that way; states that the subject could not standardly know about by recalling his decisions or recapitulating his reasoning would not be intentions. ${ }^{27}$

What about the past-tense case? As things are, we have the capacity to make immediate, groundless reports of our past intentions; both intentions that we acted on and intentions that we formed but never tried to implement. But is the capacity to make such immediate reports essential for someone's having intentions at all? To put the question in a different form, can we consistently describe people who have intentions but who have no immediate access to their own past intentions? ${ }^{28}$

Wittgenstein considers exactly this question in the following passage:

Suppose someone never said "I was going to do this then" and could not be taught to use such an expression either? ${ }^{29}$ It is surely clear that a person can think a lot without thinking that. He can master a great area of language, without mastering this one. I mean: he remembers his expressions, including perhaps that he said such-and-such to himself. So he will say, e.g., "I said to myself 'I want to go there"” and perhaps also "I imagined the house and went on the path that led there". What is characteristic here is that he has his intentions in the form of thoughts or pictures and hence that they would always be replaceable by the speaking of a sentence or the seeing of a picture. The "lightning speed" of thought is missing in him. - But now, is that supposed to mean that he often moves like an automaton; walks in the street, perhaps, and makes purchases; but when one meets him and asks "Where are you going?" - he stares at one as if he were sleep-walking? - He won’t answer "I don't know” either. Or will his proceedings strike him, or us, as planless? I don't see why!

When I go to the baker, say, perhaps I say to myself "I need bread" and I go the 
usual way. If someone asks him "Where are you going?” I want to assume that he answers with the expression of intention just as we do. - But will he also say: "As I left the house, I was meaning to go to the baker, but now ...”? No; but ought we to say that on this account he set out on his way as it were sleep-walking?

But isn't it then remarkable that, in all the great variety of mankind we do not meet such people as this? Or are there such people among the mental defectives; and it is merely not sufficiently observed which language-games these are capable of and which not? (RPP i 178-9)

The case Wittgenstein imagines seems to be this. The person behaves purposively and intelligibly; he does not behave like a mere automaton; he has, and acts on, intentions. Furthermore, it seems that he can set out with one intention, then change his mind and act on a different intention. He can give reports of his current intentions "just as we do"; so he satisfies the condition that possessing intentions requires the ability to make immediate, ungrounded judgements about one's current intentions. What he lacks is just the ability to give an immediate, non-inferential report of a past intention - either one on which he acted or one that he never tried to implement; "he can never remember an intention except by remembering the expression of an intention” (RPP i 225). If Wittgenstein's idea is, as it appears to be, that all this is coherently imaginable, then it looks as though he does not think that the ability to make immediate reports of one's past intentions plays a constitutive role: either in the weaker sense that direct access to one's past intentions is an essential condition for possessing intentions; or in the stronger sense that facts about one's past intentions are directly constituted by the reports one is disposed to make. ${ }^{30}$

Should we conclude that, though we do in fact have the ability to make immediate reports of our past attitudes, that ability is not essential for the possession of intentional states - either in Wittgenstein's view or in fact? That would be too quick, for a number of reasons.

First, the quoted discussion from Wittgenstein is evidently tentative and experimental. And, rather than offering a view, he asks a series of rhetorical questions which he leaves unanswered. The man he describes would evidently be very different from us. Wittgenstein need not have had a view about whether the differences would be so great that the concept of intention could not properly be applied to him.

Second, Wittgenstein's thought-experiment focuses on memory of intentions with which we acted and memory of unimplemented intentions. He imagines those forms of memory altogether lacking. But, as he describes the case, the subject who has no memory of his former intentions does not lack all memory of intentional facts about himself. Faced with the question, "Where was I intending to go?”, the subject cannot simply remember that he was intending to go to the house. But he can "remember his expressions [Äußerungen]": so, for example, he can remember that he said to himself "I want to go there"; and ("perhaps") he can remember that he imagined the house and went on the path that led there. Here Wittgenstein seems to take it for granted that the subject remembers, say, walking (or that he walked). And remembering walking is remembering something under an intentional description; the subject 
does not merely remember his body moving in such-and-such a way and have to figure out whether or not that (series of) bodily movement(s) was an action. So even if the thoughtexperiment is fully coherent, it does not show that we can make sense of the idea of a person who entirely lacks the capacity to remember any of his past intentional properties. Its focus is more limited than that.

Third, independently of Wittgenstein's own treatment of the thought-experiment, it might be argued that there are limits to how far it is possible for someone who genuinely possesses intentional states to lack the capacity to remember their intentions, beliefs, wishes and so on. It is easy to make sense of the idea of someone who is much worse than we are at remembering what they intended or wished a year, or a month, or a week ago; someone whose only way of knowing what they intended or wanted then is to interpret their past actions as they interpret the actions of others. But how well can we make sense of the idea of someone who simply has no capacity to remember any of their past intentional states? We might argue that we cannot make sense of that idea at all. The argument might go like this. "An intention is a state that rationally controls action and practical reasoning. And it can only play that role if one can keep track of it over time. If one forgot one's intentions as soon as one had formed them, one could not plan one's actions in the light of one's intentions, one could not monitor one's intentions and revise them in the light of subsequent developments, and - crucially - one could not act at a later stage on an intention that one had formed earlier. But if one could not do any of that, one could not engage in practical reasoning and rational action at all. A simple example illustrates the point. Suppose I go to the kitchen with the intention of collecting my razor but that, by the time I arrive, I have forgotten why I came. Because I have forgotten my intention to collect my razor, the intention can play no rational role in controlling my action; I do not know what to do in the kitchen because I cannot remember why I came. In this case, the action-stultifying failure of memory is limited to a single intention. But if I could never remember any of my intentions, all action would be impossible.”31

The argument is correct as far as it goes. But it trades on an ambiguity in the idea of remembering an intention. ${ }^{32}$ In one sense, remembering an intention is simply a matter of retaining an intention I have formed earlier. In another sense, remembering an intention is a matter of remembering that I had that intention at some earlier time, whether or not I still have it. And the considerations just advanced only give us a reason to think that reasoning and action require one to remember one's earlier intentions in the first sense. Suppose that I form the intention in February to take my brother out for dinner in October. As long as I go on intending to take him to dinner in October I will be able to reason and plan as I need to: keeping my diary free for the day, making the booking and, when the times comes, going for the meal. But that does not require that, at each stage, I should not only retain the intention to take my brother to dinner but also know that I have had that intention at each previous stage. Of course I can in fact remember my intentions in this stronger sense too: as the day of the dinner draws near, it is not just that I still intend to take my brother to dinner; I also remember having formed that intention in February and having had it since then. But is this further level 
W Child - "Memory, Expression, and Past-Tense Self-Knowledge” - Philosophy and Phenomenological Research, 73, 2006, 54-76

of memory actually necessary for action and practical reasoning?

Things would certainly be very different if we lacked the further level of memory. For example, if I were engaged in some extended action, I would at each stage know the intention with which I was acting at that stage; so I could plan what I needed to do next to fulfil my intention. But at each stage I would not remember what I had intended to do before. So, though I would frequently find myself in situations where my past actions had prepared the way for what I now intended to do, I would not know that the reason why those actions coordinated so conveniently with my present intentions was that I had performed them as earlier stages in the implementation of the plan I was still pursuing. Or again, if I could not remember what I had intended to do at an earlier time, I would have no direct way of telling whether or not I had succeeded in doing what I intended. Would this matter? We are familiar with cases in which I do something intentionally without knowing that I have succeeded in implementing my intention. But the standard cases are ones where I know what I intended to do, but do not know what I have achieved. ${ }^{33}$ What we are contemplating is the reverse phenomenon: I know what my action has achieved; but I do not know whether that counts as success because I do not know what I intended to do when I performed the action. That can happen in particular cases; it is perfectly possible to know what I have achieved even when I have forgotten what I was trying to do. Perhaps it could be shown that such cases must be exceptions - so that the general ability to remember what one intended to do in the recent past (at least) is a necessary condition for rational action. But nothing we have seen so far suggests how such an argument would go.

To sum up. As things are, we have two capacities: the capacity to retain an intention formed at one time and to reason and act on it at later times; and the capacity to know immediately about the intentions, wishes and so on that we had at particular past times. The first capacity is certainly essential for the possession of intentions. But what of the second capacity? We can certainly conceive of people who have intentions but whose ability to remember what they previously intended is much more restricted than ours. And we have found no reason of principle for thinking that the ability to engage in practical reasoning and rational action could not survive in the complete absence of the second capacity. ${ }^{34}$

\section{4.iii.c The past-tense case: concept-acquisition}

We have a practice of making past-tense self-ascriptions of intentions. But how do we get the concept of a past intention? How do we get the concept of a past intention that the agent never attempted to implement? And on what basis do we come to apply these concepts to ourselves and others?

Wittgenstein's answer to these questions starts with the thought that we acquire the concept of our past intentions by learning to produce the utterances that we come to understand as reports of those intentions. So the language-game of producing those utterances is (or starts off as) a "proto-phenomenon" (PI §654) - it is "the proto-type of a way of thinking, not the result of thought” (Z 541). That is the lesson for concept-acquisition of his 
W Child - "Memory, Expression, and Past-Tense Self-Knowledge” - Philosophy and Phenomenological Research, 73, 2006, 54-76

claim that the language-game of reporting or confessing intentions is the primary thing:

How does anyone learn to . . . understand the order "Throw!"; and how, the expression of intention "Now I am going to throw"? Well - the grown-ups may perform before the child, may pronounce the word and straightway throw, - but now the child must imitate that. ("But that is the expression of intention only if the child really has the intention in its mind" - But then when does one say that that is the case?)

And how does it learn to use the expression "I was just about to throw"? And how does one know that it was then really in the state of mind that I call "being about to throw"? After such-and-such language-games have been taught it, then on suchand-such occasions it uses the words that the grown-ups spoke in such cases, or it uses a more primitive form of expression, which contains the essential relations to what it has previously learnt, and the grown-ups substitute the regular form of expression for the more primitive one (RPP i 163).

This model, like Wittgenstein's model for acquiring the concept of pain (in both firstperson and third-person applications), is anti-intellectualist. And as in the case of other minds, we can ask two questions: How much can be claimed for this model of conceptacquisition; and how much does Wittgenstein claim? He clearly suggests that, as things actually are, we do come to grasp the concept of our past intentions in part by being trained to produce immediate, non-inferential reports of our past intentions. ${ }^{35}$ And he certainly thinks that we could not get the concept of a past intention by inspecting our conscious experiences. $^{36}$ But does Wittgenstein think that the concept of a past intention must be acquired in the way we have sketched - so that someone could not grasp the concept if they could not master the art of making immediate, ungrounded reports of those intentions? And would it be plausible to make the stronger claim?

How might we acquire the concept of a past intention if not in the way that Wittgenstein suggests? One idea would be that we could start with a present-tense conception of intention and explain the past-tense claim in terms of that, appealing to the principle: "I intended" tells of just the same thing in the past as "I intend" in the present. ${ }^{37}$ But, Wittgenstein argues, the suggested explanation is hopeless. The stated principle is true. But it cannot be used to impart the concept of a past intention to someone who does not already possess it. For in order to understand the principle, I must already know what it is for me to have been, in the past, in a state of the same kind as the state I am now in when I intend to $\Phi$. And if I really do not understand what it means to say "In the past, I intended to $\Phi$ ", that is precisely what I am lacking.

If Wittgenstein's argument is right, we cannot get the concept of a past intention merely by exploiting the simple principle; we need some independent grip on the conditions under which it is true to say "I intended to $\Phi$ ". It might then be suggested that grasp of those conditions must come from memory; so in order for our concept of intention to have a pasttense application, there really must be some cases in which we have immediate access to a past intention. 
But the suggestion is unwarranted, for two reasons. In the first place, we may doubt the cogency of Wittgenstein's argument. It is certainly true that one cannot distil the concept of the past from a purely present-tense conception of what it is for a state of affairs to obtain: the idea that we could acquire our whole concept of the past simply by being told " "It was the case that p' is true if and only if 'It is the case that p' was true” is obviously hopeless. ${ }^{38}$ And it is plausible that grasp of the very idea of the past does require one to have immediate knowledge, via memory, of at least some past states of affairs: if someone had no memory at all, and their experience was confined to awareness of how things presently are, how could they so much as form the concept of the past? But it is one thing to make a very general claim about the dependence of the concept of the past on possession of some immediate mode of access to some past states of affairs. It is another thing to claim that, for each concept of a kind of past-tense state of affairs that one grasps, one must have immediate access to some past states of affairs of that type. If someone already grasps the general distinction between past and present, and understands what it is for someone to intend to do something, it is not clear why she should not on that basis be able to grasp what it is for someone to have intended to do something in the past.

Second, even if we accept the Wittgensteinian argument, we cannot conclude that grasp of the concept of a past intention requires direct access to one's past intentions. The argument aims to show that having the concept of a past intention requires a grasp of the circumstances under which it can be said that someone intended to $\Phi$ which goes beyond mastery of the simple principle, “'I intended to $\Phi$ ' tells of just the same thing in the past as 'I intend to $\Phi$ ' in the present". But, on the face of it, someone can satisfy that condition without having any direct access to her own past intentions. She might regard her own past behaviour as she regards the past behaviour of others, learn about the complex ways in which past intentions relate to past behaviour (including past expressions of intention), and learn to ascribe past intentions to herself using the same interpretative methods she employs in ascribing past intentions to others. In that way, she could acquire the concept of her own past intentions without relying on any ability to make groundless self-ascriptions of past intentions - just as, we speculated, someone with autism could acquire the concept of others' pain without relying on any natural tendency to respond to others with sympathy and concern.

I conclude that we have been given no reason to think that the only way for a subject to acquire the concept of her past intentions involves learning to make immediate, ungrounded reports of those intentions.

\section{Common sense and retrospective constitution}

What connects a past thought or attitude to its object? The realist about past intentional phenomena thinks that, whatever it is, it must be something that was true of the subject at the time she had that thought or attitude. A series of comments in Wittgenstein may suggest a less realist view. There is, for example, the idea that a subject's judgement about an earlier remark may make a connection between that remark and its object rather than (or as well as) 
describing the connection. ${ }^{39}$ And there is the suggestion that "if I have two friends with the same name and am writing one of them a letter ... the fact that I am not writing it to the other" may consist in "what follows the writing” ( $\mathrm{Z}$ §7).

It is sometimes suggested that there is really nothing counterintuitive about the idea that intentional connections may be set up after the event. On this view, what the realist presents as an affront to common sense is actually an ordinary fact of everyday experience. Consider what Wittgenstein says in passages such as the following:

It's like searching for a word when you are writing and then saying: "That's it, that expresses what I intended!” - Your acceptance certifies the word as having been found and hence as being the one you were looking for. (In this instance we could really say: we don't know what we are looking for until we have found it -which is what Russell says about wishing.) (CV 68) $)^{40}$

On the basis of such examples, it may be claimed that there are cases that meet the following pair of conditions:

Condition (a) I was at the earlier time looking for this particular word or thing;

Condition (b) There was nothing about me at the time that made it true that I was looking for just this word or thing.

In such cases, it may be suggested, what makes it true that I was looking for just this word or thing really is my subsequent, retrospective judgement that that is what I was looking for.

Wittgenstein's remarks suggest various different kinds of case. But I shall argue against drawing any such anti-realist conclusion; there is no case in which there was at the past time a determinate thing meant, or intended, or wanted etc., but where the identity of that thing is constitutively determined by the subject's retrospective judgement.

In a first kind of case, there is a particular thing that I intend or want. But I cannot describe, or otherwise specify it; I simply have the capacity to recognize it when I see it. In such a case, when I say "That's what I was looking for”, it is true that I was looking for that particular thing at the past time; so the case meets condition (a). But in such a case, there was something about me at the time in virtue of which it was then true that I was looking for this thing; namely, that I had the capacity to recognize it as the one I meant; so this case fails condition (b). It is an important Wittgensteinian insight that a recognitional capacity for a particular thing or property may be basic and ungrounded ${ }^{41}$ : I can recognize something immediately, without comparing it with a mental template and without knowing how I recognize it. ${ }^{42}$ But we should not confuse that fact with the idea that something can be the object of my attitude at a time even though there is nothing at all about me at the time to link the attitude to that object.

In a second sort of case, the attitude I had at the past time was directed, not at a particular thing, but at whatever thing fitted some general specification. For example, I want to find the best way of arranging some new plants in a flower-bed. I try various possibilities, see that this is the best arrangement, and say: “That's the arrangement I was looking for!" There is a sense in which the claim is true: since I was looking for the arrangement that would 
look best, and this is the arrangement that looks best, we can say that this is the arrangement I was looking for. But the particular arrangement I subsequently identify as fitting the general specification did not figure in the content of the attitude I had at the time. There is, again, no question here of an intentional connection being retrospectively constituted: the case meets condition (b) but fails condition (a).

In a third sort of case, the past episode does not have a content that specifies even in general terms what it is directed towards. For example, I wake up one day feeling anxious, but without any sense of what I am anxious about. In the evening, I think about why I had the feeling. I realize that it vanished after I had completed some unpleasant task that I knew I had to perform that day. The judgement, “That's what I was anxious about!”, expresses my realization about the cause of the earlier sense of anxiety. In this case, the later judgement reveals something that was true of my sense of anxiety at the time I felt it - namely, what was causing it. But it does not tell us anything about its intentional directedness: for the feeling itself did not have a content that specified a particular object; I felt anxious, but I did not feel anxious about the unpleasant task. ${ }^{43}$ 
Finally, and relatedly, there are cases where the judgement "That's who I wanted to meet”, say, is the result of reflecting on my behaviour and ascribing myself an attitude that I had not realized I had. For example, I go to a party I would normally avoid - telling myself that I will be able to do some business with Jones. When I get to the party, I see Smith, an attractive newcomer whom I want to get to know. My reaction of pleasure makes me acknowledge an ulterior motive; “That's whom I wanted to meet!”. In this case, Smith does figure in the content of the earlier desire I self-ascribe; so the case meets condition (a). Since the earlier desire was repressed or unacknowledged, I would not earlier have identified Smith as the person I wanted to meet. Nonetheless, there was something about me at the time that made it true that it was Smith whom I wanted to meet: after all, the desire to meet Smith led me to come to a party I would normally avoid; so the case fails condition (b). When I make the later judgement, I am learning something that was already true about my earlier attitudes; I am not constituting that truth.

I conclude that none of these cases supports the idea that past intentional connections can be constituted by something the subject later says or does. Our natural, realist view remains intact. $^{44}$ 
W Child - "Memory, Expression, and Past-Tense Self-Knowledge” - Philosophy and Phenomenological Research, 73, 2006, 54-76

\section{References}

Davidson, D. 1980: Essays on Actions and Events. Oxford: OUP.

Evans, G 1982: The Varieties of Reference. Oxford: OUP.

Fricker, E. 1998: "Self-Knowledge: Special Access versus Artefact of Grammar - A

Dichotomy Rejected”, in Wright, Smith, and Macdonald 1998.

Gordon, R. 1985: "Simulation Without Introspection or Inference from Me to You”, in

Davies, M. and Stone, T., Mental Simulation: Evaluations and Applications, Oxford:

Blackwell.

Hacker, P. 2000: Wittgenstein: Mind and Will, Volume 4 of an Analytical Commentary on the Philosophical Investigations, Part II: Exegesis. Oxford: Blackwell.

Heal, J. 1994: “Moore’s Paradox: A Wittgensteinian Approach”. Mind, 103, pp. 5-24.

Heal, J. 2002: "First-Person Authority". Proceedings of the Aristotelian Society.

Kripke, S. 1981: Wittgenstein on Rules and Private Language. Oxford: Blackwell.

Moran, R. 2001: Authority and Estrangement: An Essay on Self-Knowledge. Princeton:

Princeton University Press.

Pears, D. 1987 \& 1988: The False Prison, Volumes 1 and 2. Oxford: OUP.

Pears, D. 1994: "Philosophical Theorizing and Particularism: Michael Dummett on Wittgenstein's Later Philosophy of Language”, in B. McGuinness and G. Oliveri (eds)

The Philosophy of Michael Dummett. Dordrecht: Kluwer Academic Publishers.

Pears, D. 1995a: “Wittgenstein's Naturalism”. The Monist, 78.

Pears, D. 1995b: "Wittgenstein on Philosophy and Science”, in R. Egidi Wittgenstein: Mind and Language, Dordrecht: Kluwer Academic Publishers.

Phillips, W., Baron-Cohen, S., and Rutter, M. 1998: "Understanding intention in normal development and in autism”. British Journal of Developmental Psychology,16, pp. 337-48.

Sacks, O. 1985: “The Lost Mariner”, in The Man Who Mistook His Wife for a Hat. New York: Summit Books.

Sullivan, P. 1994: “Problems for a Construction of Meaning and Intention”. Mind, 103, pp. 147-68.

Swettenham, J. 2000: "Teaching theory of mind to individuals with autism” in S. BaronCohen et al, Understanding Other Minds: Perspectives from Developmental Cognitive Neuroscience, Oxford: OUP.

von Savigny, E. 1990: “Avowals in the Philosophical Investigations: Expression, Reliability, Description”. Nous, 24, pp. 507-27.

Wittgenstein, L. BB: The Blue and Brown Books. Oxford: Blackwell, 1958.

Wittgenstein. L. CV: Culture and Value, edited by G. H. von Wright in collaboration with H. Nyman, translated by P. Winch. Oxford: Blackwell, 1980.

Wittgenstein, L. PG: Philosophical Grammar, edited by R. Rhees, translated by A. Kenny. Oxford: Blackwell, 1974 
W Child - "Memory, Expression, and Past-Tense Self-Knowledge” - Philosophy and Phenomenological Research, 73, 2006, 54-76

Wittgenstein, L. PI: Philosophical Investigations, Second Edition, edited by G. E. M.

Anscombe, R. Rhees, and G. H. von Wright, translated by G. E. M. Anscombe. Oxford: Blackwell, 1958.

Wittgenstein, L. RFM: Remarks on the Foundations of Mathematics, IIIrd Edition, edited by G. H. von Wright, R. Rhees and G. E. M. Anscombe, translated by G. E. M.

Anscombe. Oxford: Blackwell, 1978.

Wittgenstein, L. RPP i: Remarks on the Philosophy of Psychology, Volume 1, edited by

G. E. M. Anscombe and G. H. von Wright, translated by G. E. M. Anscombe.

Oxford: Blackwell, 1980.

Wittgenstein, L. RPP ii: Remarks on the Philosophy of Psychology, Volume 2, edited by G.

H.

von Wright and H. Nyman, translated by C. G. Luckhardt and M. A. E. Aue. Oxford: Blackwell, 1980.

Wittgenstein, L. Z: Zettel, 2nd Edition, edited by G. E. M. Anscombe and G. H. von Wright, translated by G. E. M. Anscombe. Oxford: Blackwell, 1981.

Wright, C 1987: “On Making Up One’s Mind: Wittgenstein on Intention”, in Wright 2001a.

Wright, C. 1989: "Wittgenstein's Rule-Following Considerations and the Central Project of Theoretical Linguistics", in Wright 2001a.

Wright, C. 1991: "Wittgenstein’s Later Philosophy of Mind: Sensation, Privacy and Intention", in Wright 2001a.

Wright, C. 2001a: Rails to Infinity: Essays on Themes from Wittgenstein's Philosophical Investigations. Cambridge, Mass.: Harvard University Press.

Wright, C. 2001b: “The Problem of Self-Knowledge”, in Wright 2001a.

Wright, C., Smith, B., and Macdonald, C. 1998: Knowing Our Own Minds. Oxford: Oxford University Press. 
W Child - "Memory, Expression, and Past-Tense Self-Knowledge” - Philosophy and Phenomenological Research, 73, 2006, 54-76

\section{NOTES}

1. The centrality of this idea is well brought out by David Pears. See his 1987 \& 1988, and 1994, 1995a and 1995b.

2. For these ideas, see PI §244 and Z 540-1.

3. See PI pp. 190-1.

4. Recent discussions of self-knowledge that draw inspiration from Wittgenstein without signing up to the less attractive features of his views include: Evans 1982; Wright 1987, 1989, 1991, 2001b; von Savigny 1990; Gordon 1995; Heal, 1994, 2003; and Moran 2001.

5. Wright is a notable exception. He explicitly considers, and is inclined to accept, the extension of his general account of self-ascription to the past-tense case. (See 1991: 314-15, and 1987: 140-2). For other discussions of the past-tense case, see Sullivan 1994, and Hacker 2000, chapters 6 and 7.

6. Of course, the fact of the matter need not be an all-or-nothing affair. My past intentions may have been mixed, or half-formed, or wavering. If so, the fact of the matter about my past intentions will not be expressible in any such simple clause as "I intended to $\Phi$ ". But that does not show that there is no fact of the matter about what my intentions were; the fact of the matter is that my intentions were mixed, or half-formed, or wavering.

7. Anti-realism of this sort has been promoted by Crispin Wright, who draws his inspiration from Wittgenstein and suggests that his view is substantially Wittgensteinian. (See the references in notes 4 and 5 above.)

8. See Z $\S 414$ for the idea that the difference between realists and idealists about material objects is "only ... one of battle cry".

9. See, for example, PI $\S \S 633 \mathrm{ff}$.

10. See $\S 637$.

11. See $\S 638$.

12. Of course there are cases in which we do reach our self-ascriptions by interpreting our past behaviour as we interpret the behaviour of others. But such cases are the exception, not the rule. (I consider in section 4.iii.b below whether such self-interpretation is necessarily the exception rather than the rule.) 
13. Elizabeth Fricker uses the example of first-person accessible bodily states to make a similar point (1998 155, n. 1). Richard Moran cites the case of bodily position to the same end $(2001,19-20)$.

\section{See RPP i 241.}

15. RPP i 160.

16. See PI $\S \S 561-8$.

17. See e.g. RPP i 366-7.

18. See RFM 193 on what "pertains to the essence of a technique".

19. See Kripke 1981.

20. A fuller treatment of the topic would need to address various other passages and lines of thought in Wittgenstein. These include: (i) Wittgenstein's suggestion that a judgement about an earlier remark may make the connection between the remark and its object, instead of (or, perhaps, as well as) describing the connection (see e.g. PI §£682-4). I discuss one aspect of this suggestion in $\S 5$ below, but it deserves more discussion; (ii) The apparently anti-realist account of past thoughts at PI pp. 222-3, where Wittgenstein seems to understand the truth of a report about what I was thinking in terms of its truthfulness or sincerity; (iii) Wittgenstein's observation that I cannot support an assertion about what I meant by appealing to what I would have said or done had I been asked at the time, and his claim that it is only a hypothesis that, had I been asked at the time how you were meant to go on, I should have said such-andsuch (e.g. PI §187 and BB pp. 142); (iv) His opposition to certain ways of appealing to dispositions (e.g. PI §§149, 156-8, BB p. 142); (v) The problem of showing how a broadly dispositional view of intentional properties is compatible with our ability to self-ascribe those properties effortlessly and accurately. (I hope to deal with some of these issues elsewhere.)

21. This is the interpretation that seems to be suggested in P. M. S. Hacker's exegesis of PI $\S 656$. See Hacker 2000.

22. See $Z \S \S 537,542$ for this epistemic point. To say that third-person ascriptions of pain are immediate and non-inferential is not to say that they are groundless. When I judge that someone is in pain, I don't infer his pain from his behaviour and its similarity to the way that I behave when I am in pain. But I do have grounds for my judgement; I tell that he is in pain by observing his situation and behaviour. 
23. See PI $\S \S 302$ and $350-1$.

24. For an interesting review of work on teaching people with autism how to ascribe attitudes to others, see Swettenham 2000.

25. This is not to say that we could not form the concept of a kind of state such that a condition for one person's being in a state of that kind is that other people have some tendency to react towards them with sympathy and concern. (Wittgenstein's imagined case of a tribe with two concepts “akin to our 'pain”” (RPP ii 638) might be developed in that way.) But that is not how our concept of pain functions.

26. Wittgenstein explicitly links this remark to his earlier comments about sensations and their natural expression; it is immediately followed with the note: "((Connexion with propositions about sensations.))”

27. For extensive development of the line of thought suggested here, see Moran 2001.

28. Some will think that the question, whether the capacity to make immediate reports of one's past intentions is essential for possessing intentions, is unWittgensteinian. But Wittgenstein is actually quite happy to distinguish between the essential and the inessential features of mental phenomena in cases of exactly this sort. See e.g. PI p. 175 and RPP i 163, 177, 282-3, 666, 871.

29. Wittgenstein is talking about the phenomenon of remembering an intention one had for a moment but then abandoned. That is clear from the context, and also from the Zettel version, which starts: "Suppose a human being never learnt the expression 'I was on the point of' or 'I was just going to ...' and could not learn their use?” (Z 43)

30. It is, again, worth mentioning the case of people with autism as a possible real-life example of the phenomenon that Wittgenstein is imagining. Experimental evidence suggests that some people with autism are extremely bad at recalling their past intentions. (Phillips, Baron-Cohen and Rutter 1998.) Such evidence might show that these subjects have not properly grasped the concept of their own past intentions. But it does not show that they do not really have intentions at all.

31. For interesting reflections on the extent to which very severe amnesia prevents rational thought and action, see Sacks 1985.

32. I am indebted here to Ralph Wedgwood. 
33. For two classic examples - writing a will with the intention of making provision for one's children, and pressing hard on the page with the intention of producing ten legible carbon copies - see Davidson 1980 90-1.

34. Even if we could show that the capacity to remember one's intentions in the stronger sense was essential for rational action, the argument would presumably apply directly only to those past intentions on which we had acted; nothing would follow about the ability to remember an intention that one had had for a moment but did not even try to implement.

35. I say "in part” because Wittgenstein does not suggest that producing appropriate reports in appropriate circumstances is sufficient for having the concept. After all, I might learn to produce the words without understanding what they meant.

36. In the first place, an intention is not an experience and cannot be inferred from experiences. But even if it were an experience, Wittgenstein thinks, one can never acquire the concept of a kind of mental state by introspection: "Introspection can never lead to a definition. It can only lead to a psychological statement about the introspector" (RPP i 212; Cf PI §314).

37. See PI p. 190. Wittgenstein there discusses the relation between "I believe" and "I believed". I have adapted his discussion for the case of intention.

38. Strictly speaking, to conceive of something as obtaining in the present builds in the idea of other times, past and future, with which the present is to be contrasted. So "purely presenttense conception" is an oxymoron.

39. See PI §§682-4. Wright quotes these sections as confirmation that it is "on the right exegetical tracks" to suggest that a subject's avowals have "a constitutive rather than descriptive role" (1987 139).

40. For further discussion of this sort of case, see PI pp. 218-19. For a related example, see RPP i 60.

41. Ungrounded, that is, at the level of conscious thought and phenomenology - which is, for Wittgenstein, the level at which philosophy (as opposed to empirical psychology) must operate.

42. See e.g. BB 85-9, PI §604. 
43. See BB 21-2. Wittgenstein allows that, if my sense of anxiety is caused by the knowledge that there is an unpleasant task to be done, then there is a sense in which I could be said to be worried about the unpleasant task. But he consistently maintains that this sense of aboutness which has to do with the causal origin of a feeling or emotion - is entirely different from the aboutness of genuine intentional connectedness.

44. An earlier version of this paper was presented at the APA Eastern Division Meeting in Washington DC in December 2003; I am grateful to Ed Minar, who responded on that occasion. Versions of some of the material were presented at the International Colloquium on Wittgenstein and 20th Century Analytic Philosophy, Peking University, in October 2002, at ECAP 4 in Lund, in June 2002, and at the Universities of Oxford, York, Bristol, Nottingham, Prague, Southampton, Birmingham, and Vercelli. I am grateful to the audiences on those occasions for many helpful comments and objections, and particularly to Anita Avramides, Tom Baldwin, Paul Boghossian, Jessica Brown, Darragh Byrne, John Campbell, David Charles, Philippa Foot, Paul Horwich, Michael Forster, Robert Kirk, Marie McGinn, Penelope Mackie, Adrian Moore, Harold Noonan, Paul Noordhof, David Owen, David Pears, Aaron Ridley, Gonzalo Rodriguez-Pereyra, Genia Schoenbaumsfeld, Ralph Wedgwood, Meredith Williams, and Tim Williamson. 